\title{
Study of Myocardial Dysfunction in Perinatal Asphyxia
}

\author{
Dr. Khushali Tanna ${ }^{1}$, Dr. Charul R. Mehta ${ }^{2 *}$, Dr. K. M. Mehariya ${ }^{3}$ \\ ${ }^{1}$ Resident Doctor, Department of Pediatrics, B. J. Medical College, Civil Hospital, Ahmedabad, India \\ ${ }^{2}$ Assistant Professor, Department of Pediatrics, B. J. Medical College, Civil Hospital, Ahmedabad, India \\ ${ }^{3}$ Professor, Department of Pediatrics, B. J. Medical College, Civil Hospital, Ahmedabad, India
}

*Corresponding Author: Charul R. Mehta, Assistant Professor, Department of Pediatrics, B. J. Medical College, Civil Hospital, Ahmedabad, India, Email: charulpurani@yahoo.in

\begin{abstract}
Aims and objective: To study an incidence of myocardial dysfunction in neonates with perinatal asphyxia, to find out its correlation with severity of birth asphyxia and its outcome.

Design/Methods: This prospective study was conducted among 40 term neonates admitted in NICU of Civil Hospital Ahmedabad who had suffered with perinatal asphyxia (defined by WHO ), resuscitated as per NRP guidelines-2015 including both intramural and extramural admissions and who developed to hypoxic ischemic encephalopathy as defined by Levene staging. Neonates with congenital heart diseases, major CNS malformations and neonatal sepsis were excluded. Myocardial involvement was assessed by clinical evaluation of CCF, shock, respiratory distress, abnormal ECG changes and cardiac markers (CK Total, CK-MB and Troponin I) measurements.

Results: Among 40 cases, 10(25\%) neonates had moderate birth asphyxia while 30(75\%) had severe birth asphyxia. Respiratory distress was observed in 34(77.5\%), poor spontaneous respiration 4(10\%), shock in 14(35\%), CCF 19(47.5\%) while ECG was abnormal in 30(76.7\%). Serum levels of CPK Total, CPK- MB and Troponin I were raised in 34(85\%), 32(80\%) and 28 (70\%) neonates, respectively. There was a direct correlation between ECG changes and enzymatic levels which showed increasing abnormalities with increasing with severity of HIE.
\end{abstract}

Conclusion: Clinical deterioration, abnormal ECG and cardiac enzymes levels due to myocardial damage found in HIE are associated with poor outcome. Early detection can help in better management and survival of these neonates. Neverthless the importance of preventing birth asphyxia itself can't be undermined, which would be a major milestone in preventing neonatal mortality.

Keywords: Birth asphyxia, myocardial dysfunction

Abbreviations:

CNS- Central Nervous System

SBA-Severe Birth Asphyxia

HIE- Hypoxic Ischemic Encephalopathy

\section{INTRODUCTION}

Perinatal asphyxia is a major cause of morbidity and mortality in India. It is an insult to the fetus or newborn due to hypoxia \& poor perfusion to various organs ${ }^{[1]}$. It causes multi organ dysfunction including myocardial dysfunction which can affectthe outcome adversely. National neonatology forum has suggested that birth asphyxia should be diagnosed when "Baby has gasping and inadequate breathing or no breathing at 1-minute" According Birth asphyxia ${ }^{[2]}$ : Apgar score of less than 7 at 1 minute of age.
$C C F$ - Congestive cardiac failure

MBA-Moderate Birth Asphyxia

NNF - National Neonatology Forum India

Moderate birth asphyxia: Apgar score between 3 to 5 at 1-minute of age 4-6 at 5 minute.

Severe birth asphyxia: Apgar score of 3 or less at 1-minute of age.

Perinatal asphyxia leading to hypoxic-ischemic encephalopathy (HIE) is still a common problem encounterd in an Indian set-up and is a major contributor for neonatal mortality. The effect of asphyxia on myocardium was described as early as 1935 by Hori H. Imai ${ }^{[3]}$. Myocardial ischemia has been demonstrated by thallium 201 myocardial perfusion scans ${ }^{[4]}$, elevated serum 
CPK MB isoenzyme ${ }^{[5,6]} \&$ histopathologically ${ }^{[7]}$ at autopsy \& in electrocardiogram In the past. Perinatal asphyxia is a common problem with the incidence ${ }^{[8]}$ varying from $0.5-2 \%$ oflive births in developed country (reported incident in various community based studies in India-2$16.2 \%$ ) and contributes for $20-30 \%$ of neonatal mortality (in India 8.7-38.4\%) In India about $2.8 \%$ and $5.6 \%$ of all live births had moderate and severe birth asphyxia.

\section{OBJECTIVE}

Tostudy an incidence of myocardial dysfunction in neonates admitted with perinatal asphyxia and tofind out its correlation with severity of birth asphyxia and its outcome.

\section{Material ANd Methods}

- Study Design: Prospective study which was conducted among 40 term neonates admitted in NICU of Civil Hospital Ahmedabad.

- Study Design: July-Aug, 2018.

- Inclusion Criteria: Newborns, who had suffered with perinatal asphyxia and resuscitated as per NRP guidelines-2015 including both intramural and extramural admissions, who developed to hypoxic ischemic encephalopathy as defined by Levene staging.

- Exclusion Criteria: Newborns with Neonates with congenital heart diseases, Neonatal sepsis and major central nervous system malformation were excluded.

All the neonates were managed in NICU as per hospital protocol. They were given oxygen by hood (5-6 1/min), nasal continuous positive airway pressure, mechanical ventilation (based on saturation of oxygen ( $\mathrm{SpO} 2)$ and Arterial Blood Gas findings), intravenous fluids, vitamin $\mathrm{K}$ and if required, inotropes (Dopamine and/or Dobutamine each by $(10-20 \mu \mathrm{g} / \mathrm{kg} / \mathrm{min})$ and anticonvulsants (Phenobarbitone $20 \mathrm{mg} / \mathrm{kg}$ as loading dose, followed by $3-5 \mathrm{mg} / \mathrm{kg} / \mathrm{day}$, and phenytoin sodium. First line antibiotics (cefosulbactam and gentamycin) were given to those cases where risk factors for sepsis were present and required mechanical ventilation. A detailed history was taken and physiological examination was done.

Myocardial involvement was assessed by clinical evaluation(congestive heart failure was diagnosed by careful examination of cardiovascular system including heart rate, character of heart sound, respiratory rate, liver size and gallop rhythm, shock diagnosed by cold extremities, weak femorals, pallor, capillary refilling time and respiratory distress was diagnosed by intercostal and subcostal retraction, expiratory grunting. and investigations like ECG and cardiac markers (CK Total(25-200IU/L), CK-MB(0-25IU/L) and Troponin I(0-0.03ug/L)) measurements.

\section{Results}

In this study after clinical evaluation as described before, Newborns with perinatal asphyxia categorized according to definition in newborn with moderate birth asphyxia are $10(25 \%)$ and with severe birth asphyxia 30(75\%). These patients had required different modes of resuscitation like Initial step of resuscitation in 6 patients (15\%), bag and mask ventilation was required in 20 patients $(50 \%)$ and $\mathrm{Bag}$ and tube ventilation with chest compression was needed in 14 patients $(35 \%)$

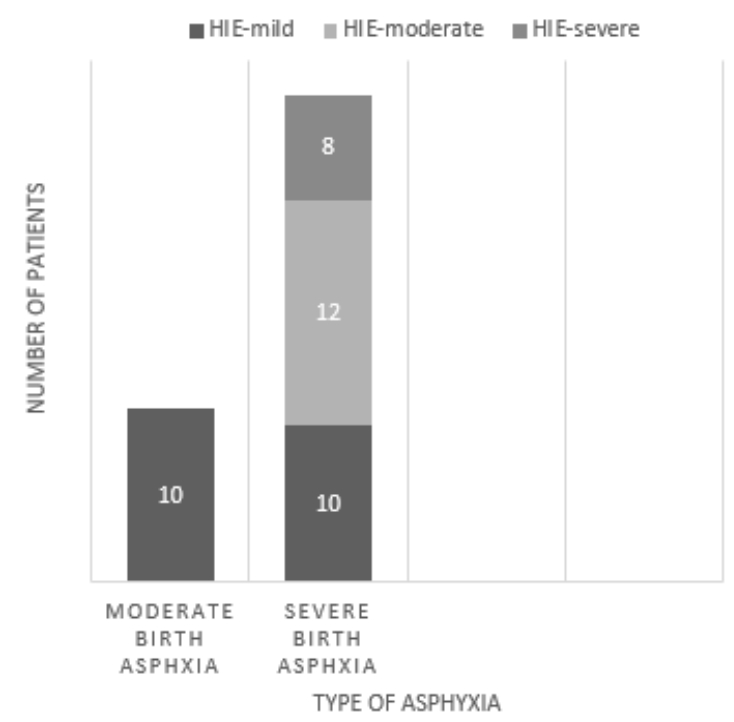

The various clinical features related to cardiac dysfunction respiratory distress, congestive cardiac failure and shock with lab investigation, chest X-ray (cardiomegaly) and ECG (Prolonged QRS (> $0.06 \mathrm{sec}$ ), RBBB and LBBB. Abnormal Q wave (amplitude of Q 25\% or more of following $\mathrm{R}$ wave or Q wave $4 \mathrm{~mm}$ of more in depth. Abnormal ST segment (ST segment depression or elevation $1 \mathrm{~mm}$ or more in standard leads or $2 \mathrm{~mm}$ or more in chest leads, $\mathrm{T}$ wave changes (Flat or inverted $\mathrm{T}$ wave except in avR)) were evaluated in these patients. 
Electrocardiographic changes in birth asphyxia have similarly been described by Richard D. Rowe $^{[8]}$, S.R. Daga ${ }^{[9]}$, H. Gidwani ${ }^{[10]}$ etc in the past.
Results suggest, myocardial dysfunction assessed by above parameters was observed in 27 newborns with severe birth asphyxia and 4 newborns with moderate birth asphyxia.

Distribution of patients observed with such signs and lab investigations as below

\begin{tabular}{|c|c|c|c|c|}
\hline \multirow[t]{2}{*}{ Birth Asphyxia } & \multicolumn{3}{|c|}{ Severe Birth Asphyxia } & \multirow{2}{*}{$\begin{array}{c}\text { Moderate Birth } \\
\text { Asphyxia }\end{array}$} \\
\hline & HIE-1 $(n=10)$ & HIE-2 (n=12) & HIE-3 (n=8) & \\
\hline Respiratory Distress & $7(70 \%)$ & $12(100 \%)$ & $8(100 \%)$ & $4 / 10(40 \%)$ \\
\hline $\mathrm{CCF}$ & $4(40 \%)$ & $7(58.8 \%)$ & $7(87.5 \%)$ & $1 / 10(10 \%)$ \\
\hline Shock & $1(10 \%)$ & $5(41.66 \%)$ & $7(87.5 \%)$ & $1 / 10(10 \%)$ \\
\hline ECG Changes & $7(70 \%)$ & $11(91.66 \%)$ & $8(100 \%)$ & $1 / 10(20 \%)$ \\
\hline Cardiomegaly & 0 & $3(25 \%)$ & $5(62.5 \%)$ & $1 / 10(10 \%)$ \\
\hline Elevation of Cardiac Markers & $7(70 \%)$ & $11(91.66 \%)$ & $8(100 \%)$ & $2 / 10(20 \%)$ \\
\hline
\end{tabular}

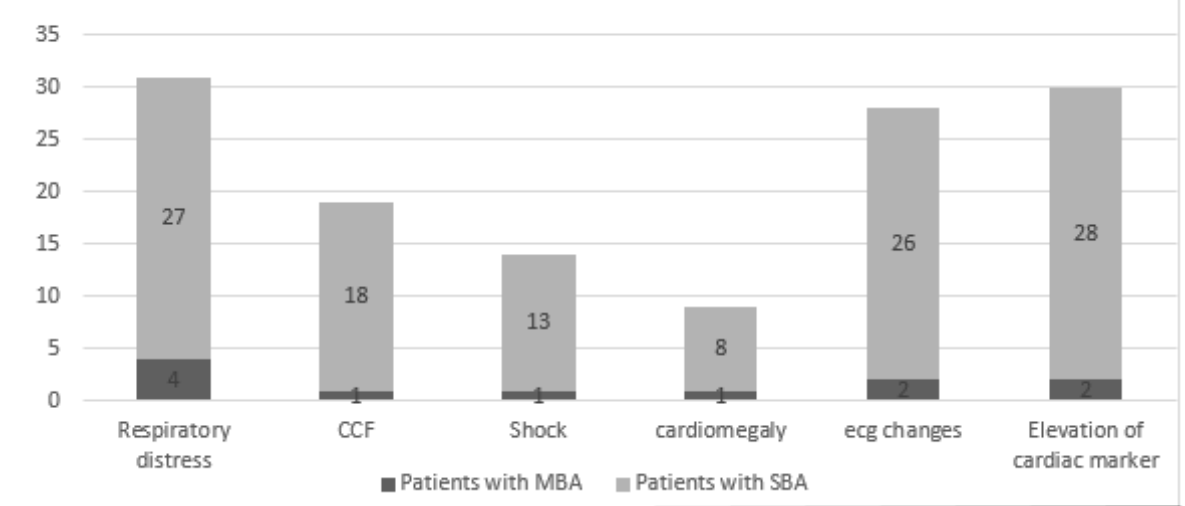

Out of 28 patient with severe birth asphyxia and myocardial dysfunction, 11(39.2\%) were expired and no any mortality observed in patients with moderate birth asphyxia.

\section{CONCLUSiON}

There was a direct correlation between clinical deterioration, ECG changes and enzymatic levels which showed increasing abnormalities with increasing with severity of asphyxia and HIE. Clinical deterioration, abnormal ECG and cardiac enzymes levels due to myocardial damage found in birth asphyxia are associated with poor outcome. Early detection can help in better management and survival of these neonates. Nevertheless the importance of preventing birth asphyxia itself can't be undermined, which would be a major milestone in preventing neonatal mortality.

\section{REFERENCES}

[1] Cloherty JP, Snyder EY. Perinatal asphyxia. Manual of Neonatal Care. 7Edition, Wolters Kluwer Publication 2012; 55:711-27.

[2] NEONATAL - PERINATAL DATABASE World Health Organization (South-East Asia Region) defined birth asphyxia.
[3] Hori H, Imami M, Safo M. On the Electrocardiogram of Newborn, Second report on the ECG of the asphyxiated newborn, Jap .J.Obst.Gynaec.1935; 18:333-9.

[4] Finley JP, Howman-Giles RB, Gilday DL, Bloom KR, Rowe RD. Transient myocardial ischemia of the newborn infant demonstrated by thallium myocardial imaging. J Pediatr. 1979; 94(2):263-70.

[5] Jyoti Agarwal, Gauri S Shah, Prakash Poudel, Nirmal Baral, Ajay Agrawal and Om P Mishra. Electrocardiographic and enzymatic correlations with outcome in neonates with Hypoxic Ischaemic Encephalopathy. Italian journal of Pediatrics. 2012; 38; 33.

[6] Tapia-Rombo CA, Carpio-Hernández JC, Salazar- Acuña AH, Alvarez-Vázquez E, Mendoza-Zanella RM, Pérez-Olea V, RosasFernández C. Detection of transitory myocardial ischemia secondary to perinatal asphyxia. Arch Med Res. 2000; 31(4):377-83.

[7] Bancalari A, Otero C, Bello P, Soto G, Pandolfi E, León L. Myocardial damage following neonatal severe asphyxia. Rev Chil Pediatr. 1991; 62(4):232-7.

[8] Rowe R.D. Hoffman T. Transient myocardial ischemia of the newborn infant: a form of severe cardiorespiratory distress in full tern infants. $\mathbf{J}$ Paediatr.1972; 81(2):243-50. 
[9] Daga SR, Wagholokar UL. Clinicopathological correlation in neonatal myocardial ischaemia. Indian J Pathol Microbiol. 1986; 29(3): 297:301.
[10] Gidvani CH, Raju U, Chandar V, Ghosh B, WilsonCG. ECG changes in asphyxia neonatorum. India Pediatr. 1990; 27(11):1177: 81.

Citation: Khushali Tanna, Charul R. Mehta, K. M. Mehariya, Study of Myocardial Dysfunction in Perinatal Asphyxia. ARC Journal of Pediatrics. 2018; 4(2): 13-16. doi:dx.doi.org/10.20431/2455-5711.0402003.

Copyright: (C) 2018 Authors. This is an open-access article distributed under the terms of the Creative Commons Attribution License, which permits unrestricted use, distribution, and reproduction in any medium, provided the original author and source are credited. 